Endocrinol. Japon. Vol. 6, No. 1 (1959)

\title{
STUDIES ON THE PHYSIOLOGICAL CHEMISTRY OF THE SALIVARY GLANDS XXXVIII* PROTEOLYTIC AGTIVITY OF HUMAN SALIVA
}

\author{
YOSOJI ITO, SEIYU HIROSE, ${ }^{* *}$ AND KEIKO TAKEUCHI \\ Department of Physiological Chemistry, Faculty of Pharmaceutical \\ Sciences, University of Tokyo
}

Recently it was reported that submaxillary gland homogenate of rat degraded ${ }^{131}$-labeled Parotin, growth hormone, and casein with remarkable rapidity as compared with kidney, liver, spleen, pancreas, testis, muscle, and parotid gland homogenates. This rapid degradation of the labeled proteins by rat submaxillary homogenate was found to be proteolytic in nature, by quantitative paperchromatographic analysis (Kim, 1958).

Concerning to the proteolytic activity in human saliva, no study has been found except the early work by Voss (1931).

This paper deals with the occurrence and some characteristics of the protease in human saliva, using $\mathrm{I}^{131}$-labeled casein as substrate.

\section{MATERIALS AND METHODS}

Preparation of I $^{131}$-labeled casein The techniques employed in trace labeling of casein (Kasein nach Hammarsten, E. Merk) were almost similar to those previously reported (Tanaka and Ito, 1958). A hundred and fifty $\mathrm{mg}$ of casein were dissolved in $30 \mathrm{ml}$ of $M / 10$ phosphate-borate buffer, pH 8.8. Separately, $10 \mathrm{ml}$ of $0.002 \mathrm{~N} \mathrm{Kl}$ labeled with ca. $10 \mathrm{mc}$ of $\mathrm{I}^{131}$ were oxidized with nitrous acid $\left(1.0 \mathrm{ml}\right.$ of $0.15 N \mathrm{NaNO}_{2}$ and $2.0 \mathrm{ml}$ of $\left.0.18 \mathrm{~N} \mathrm{H}_{2} \mathrm{SO}_{4}\right)$, the excess nitrous acid being destroyed with $1.0 \mathrm{ml}$ of $1 \mathrm{~N}$ ammonium sulfamate. This iodine solution was made slightly alkaline with $0.2 \mathrm{~N} \mathrm{NaOH}$ and mixed with the above casein solution, and was kept at $26^{\circ}-27^{\circ} \mathrm{C}$ for $2.5 \mathrm{hrs}$. After the addition of $1.5 \mathrm{ml}$ of $0.02 \mathrm{~N} \mathrm{Na}_{2} \mathrm{~S}_{2} \mathrm{O}_{3}$, this reaction mixture was dialized against ice-cold distilled water adjusted to $\mathrm{pH} 8$ for a day, adding, at intervals, about $1 \mathrm{ml}$ of $0.2 \mathrm{~N} \mathrm{Kl}$ as carrier into the inside phase. Then the labeled casein, contained in the inside fluid, was precipitated twice at the isoelectric point, and the dialysis against ice-cold distilled water was repeated once. After lyophilization of the solution, purified I I31labeled casein was obtaincd.

The purity of the labeled casein as expressed by the per cent of the total radioactivity found in trichloroacetic acid (TCA) precipitable fraction was 98-99\%. About 30\% of the initially used $\mathrm{I}^{131}$ was found to be combined with the casein.

Collection of saliva Human mixed saliva, collected directly into an ice-cold cylinder, was used without centrifugation. The midmorning saliva was used throughout all experiments.

Method of estimation of the proteolytic activity of human saliva $\mathrm{I}^{131}$-labeled casein was dissolved in distilled water adjusted to $\mathrm{pH} 8(200 \mu \mathrm{g} / \mathrm{ml}, 400 \mu \mathrm{g} / \mathrm{ml})$. One half $\mathrm{ml}$ of this solution

Received for publication January 24, 1959.

* XXXVII : Y. Ito, Y. Kubota and Y. Shibuya (1959). J. Biochem. in press.

* Previous name: Seiyu Tanaka 
was mixed with $0.5 \mathrm{ml}$ of $M / 10$ phosphate buffer, $\mathrm{pH} 7.2$ and $1.0 \mathrm{ml}$ of saliva in a small test tube, and aerobically incubated at $37^{\circ} \mathrm{C}$ for the designated periods. When the incubation was over, tubes were cooled in ice-cold water for several mins., and $0.5 \mathrm{ml}$ of casein solution (TCAcarrier casein: usually $30 \mathrm{mg} / \mathrm{ml}$ ) and $2.5 \mathrm{ml}$ of $10 \%$ TCA were added to each tube. After centrifugation, the supernatant fluid was transferred to another test tube (specially prepared for the gamma-counting experiments, i.e. having three marks at 2, 4, and $6 \mathrm{~cm}$ from the bottom), neutralized with sodium hydroxide solution, and the radioactivity was assayed with a well-type scintillation counter in relation to the total $\mathrm{I}^{131}$-casein added to each test tube.

Quantitative radio-paperchromatography Saliva ( $1 / 2 \mathrm{final}$ concent.) and $\mathrm{I}^{131}$-casein $(500 \mu \mathrm{g} / \mathrm{ml}$ final concent.) were incubated at $37^{\circ} \mathrm{C}$ and $\mathrm{pH} 7.2$ for $3 \mathrm{hrs}$. The incubation mixture was centrifuged at low temperature without the addition of TCA solution, and the supernatant fluid was spotted on a filter paper in $2 \mathrm{~cm}$ width and developed in 95\% ethanol and $2 \mathrm{~N}$ ammonia (90:10) for about $12 \mathrm{hrs}$. After being dried, each paper was cut into 21 fragments along the $\mathrm{Rf}$ value (Fig. 1). Radioactivity in each fragment was assayed separately or in groups with a well-type scintillation counter, as per cent of the total radioactivity of 21 fragments.

\section{RESULTS AND DISCUSSION}

Upon incubation of $\mathrm{I}^{131}$-labeled casein with human saliva at $\mathrm{pH} 7.2$, there was a rapid rise in the radioactivity in the TCA supernatant fluid. This is demonstrated in Figure 2. The increased supernatant radioactivity was thought to

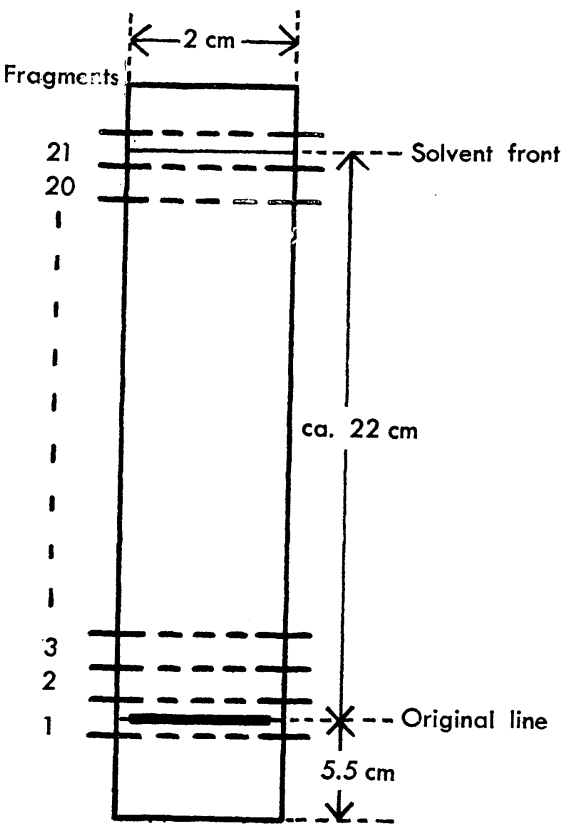

Fig. 1. Quantitative radio-paperchromatography

Radioactivity of each fragment was assayed separately or in groups with a well-type scintillation counter avoiding the geometrical error.

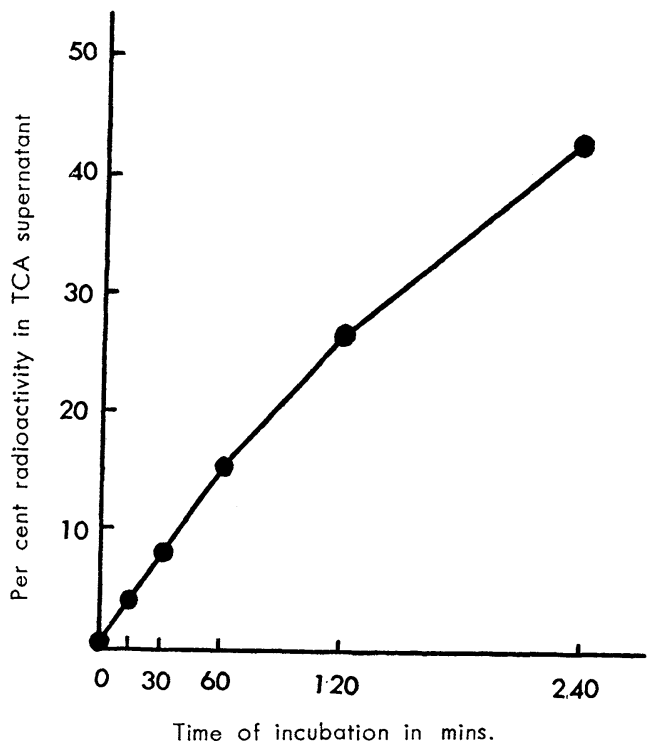

Fig. 2. Degradation of $1^{131}$-labeled casein by human saliva

Incubation of $I^{131}$-casein $(100 \mu \mathrm{g} / \mathrm{ml}$ final concent.) and saliva $(1 / 2$ final concent.) at $37^{\circ} \mathrm{C}$ and $\mathrm{pH} 7.2$ for the designated periods; TCA-carrier casein $(6 \mathrm{mg} / \mathrm{ml}$ final concent.) 
be either the result of proteolysis or of direct deiodination of the labeled casein. By the quantitative radio-paperchromatography, the former mechanism. i.e. proteolytic degradation, was demonstrated as shown in Figure 3. In the case of nonincubated $\mathrm{I}^{131}$-casein, almost all radioactivity was found around the original line $(\mathrm{Rf}$ $-0.025-0.025)$, while iodide ion labeled with $I^{131}$ appeared in the highest $\mathrm{Rf}$ area $(\mathrm{Rf}$ $0.875-1.025)$. In the case of $\mathrm{I}^{131}$-casein incubated with human saliva at $37^{\circ} \mathrm{C}$ and pH 7.2 for $3 \mathrm{hrs}$., approximately $70 \%$ of the total radioactivity was found around the original line and considerable amounts of radioactivity were observed in the higher $\mathrm{Rf}$ areas. But in the highest $\mathrm{Rf}$ area $(\mathrm{Rf} 0.875-1.025)$ where radioactive iodide
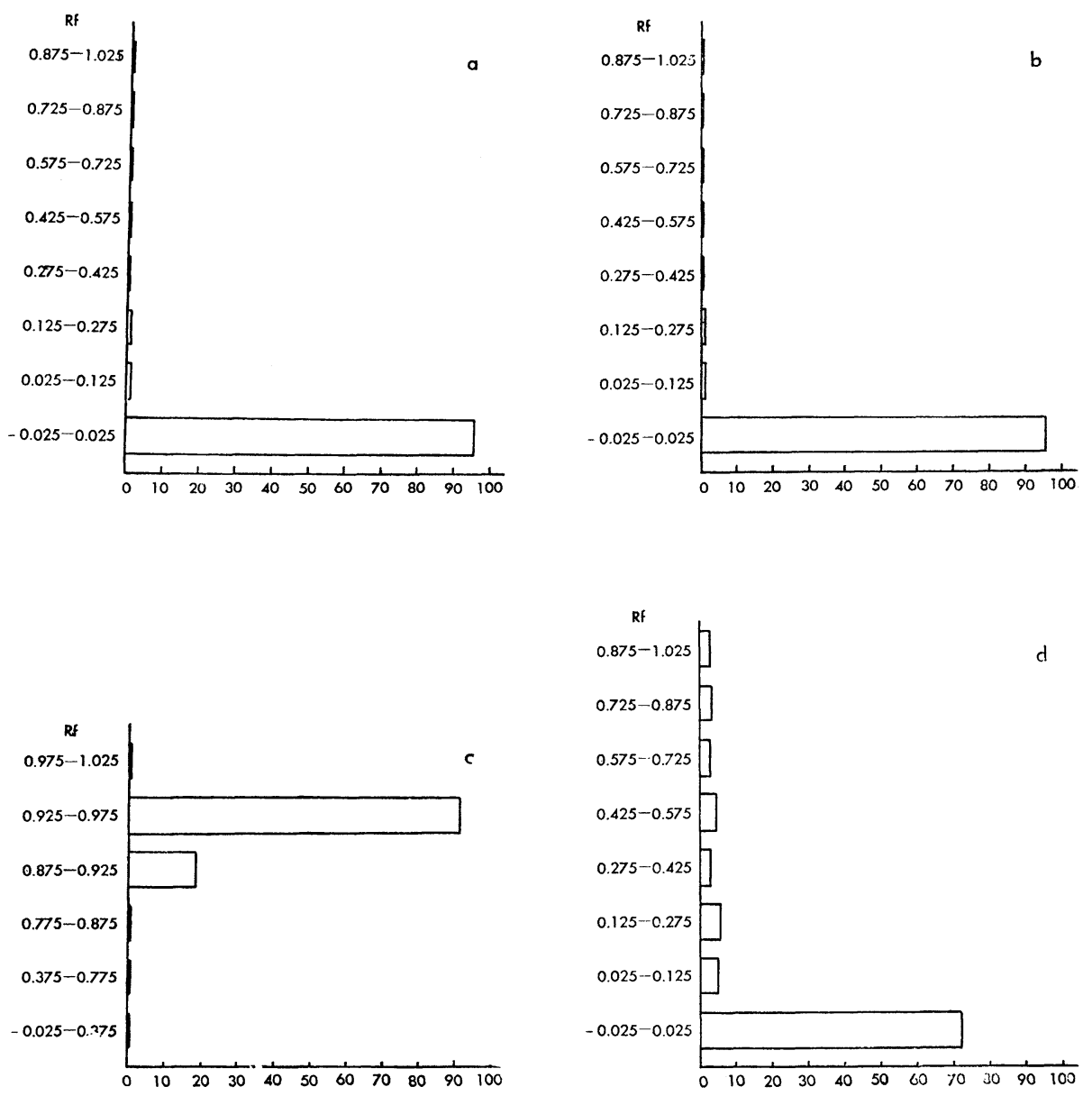

Fig. 3. Quantitative radio-paperchromatographic analysis of the mode of degradation of $\mathrm{I}^{131}$-casein by human saliva

Abscissas: Per cent radioactivity in each designated $\mathrm{Rf}$ area

a: $1^{131}$-casein non-incubated (control)

b: $\quad{ }^{131}$-casein mixed at low temperature with similarly preincubated saliva (control)

c: lodide ion labeled with $\mathrm{I}^{131}$

d: $\quad^{131}$-casein incubated with saliva; incubation of $\mathrm{I}^{131}$-casein $(500 \mu \mathrm{g} / \mathrm{ml}$ final concent.) and saliva $1 / 2$ final concent.) at $37^{\circ} \mathrm{C}$ and $\mathrm{pH} 7.2$ for $3 \mathrm{hrs}$. 


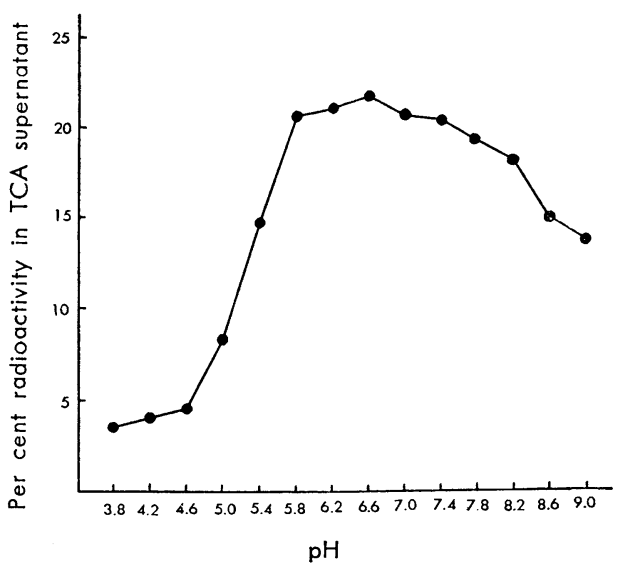

Fig. 4. Effect of $\mathrm{pH}$ on the proteolytic activity of human saliva

Incubation of $\left.\right|^{131}$-casein $(50 \mu \mathrm{g} / \mathrm{ml}$ final concent.) and saliva ( $1 / 2$ final concent.) at $37^{\circ} \mathrm{C}$ and the designated $\mathrm{pHs}$ for $2 \mathrm{hrs}$.; TCA-carrier casein $(6 \mathrm{mg} / \mathrm{ml}$ final concent.)

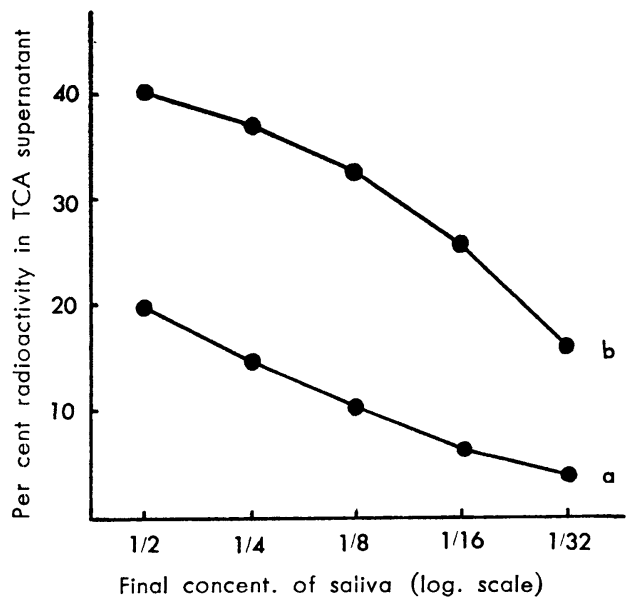

Fig. 5. Effect of concentration of saliva on the degration of $\left.\right|^{131}$-casein

Incubation of $1^{131}$-casein $(50 \mu \mathrm{g} / \mathrm{ml}$ final concent.) and saliva at $37^{\circ} \mathrm{C}$ and $\mathrm{pH} 7.2$ for $1 \mathrm{hr}$. (a) or $3 \mathrm{hrs}$. (b); TCA-carrier casein ( $6 \mathrm{mg} / \mathrm{ml}$ final concent.) ion was developed, scarcely any radioactivity was found. Therefore, it was concluded that the degradation of the labeled casein by human saliva was not deiodinative but proteolytic in nature. In addition, these results of paperchromatographic study seemed to be in good agreement with the finding that about $23 \%$ of the total radioactivity was observed in the TCA supernatant fluid, following the simultaneous incubation of the labeled casein with saliva under the same conditions.

The effect of $\mathrm{pH}$ on the proteo. lytic activity of human saliva, as measured by the per cent radioactivity in TCA supernatant fluid, was determined at fourteen different pHs, ranging from 3.8 to 9.0 (Fig. 4). The activity was found maximal

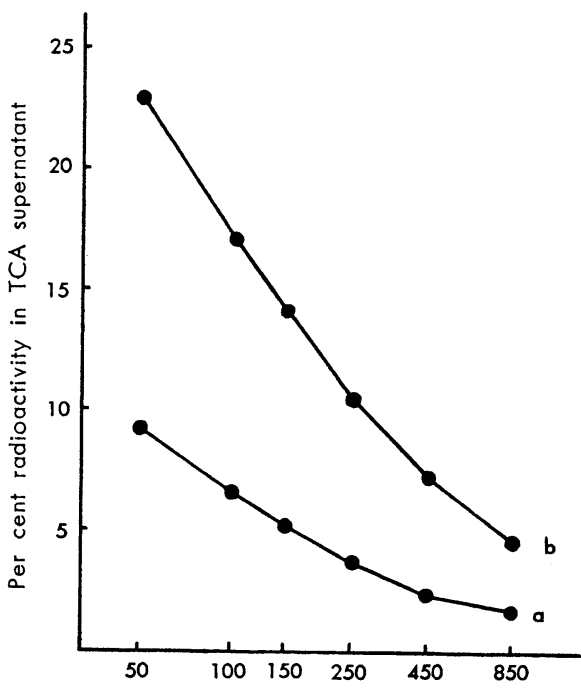

Final concent. of substrate ( $\mu$ g perml, log. scale)

Fig. 6. Effect of substrate concentration on the degradation of $\mathrm{I}^{131}$-casein by human saliva

Incubation of $\left.\right|^{131}$-casein $(50 \mu \mathrm{g} / \mathrm{ml}$ final concent.), casein $(0,50,100,200,400$, and $800 \mu \mathrm{g} / \mathrm{ml}$ final concent.) and saliva ( $1 / 2$ final concent.) at $37^{\circ} \mathrm{C}$ and $\mathrm{pH} 7.2$ for $1 \mathrm{hr}$. (a) or $3 \mathrm{hrs.} \mathrm{(b);} \mathrm{TCA-carrier}$ casein $(6 \mathrm{mg} / \mathrm{ml}$ final concent.) 
at pHs between 6 and 8, rapidly dropping on either side of the maximum. Consequently $\mathrm{pH} 7.2$ was adopted for the usual assay of the proteolytic activity of human saliva.

That the degradation of $\mathrm{I}^{131}$-casein was related to the quantity of the enzyme present in the incubation mixture was revealed when the same amount of the labeled casein was incubated with variously diluted saliva at $37^{\circ} \mathrm{C}$ and $\mathrm{pH} 7.2$ for 1 or 3 hrs. (Fig. 5).

The effect of substrate concentration on the degradation of $\mathrm{I}^{131}$-casein by saliva was studied by incubating the same amount of saliva plus labeled casein with different amounts of casein as shown in Figure 6 . It was found that not only the degradation of the labeled casein as expressed by the per cent radioactivity in TCA supernatant, was related to the substrate concentration, but $1^{131}$-casein and casein were similarly degraded by saliva. And the latter also seemed to support the conclusion that the labeled casein was degraded proteolytically by human saliva.

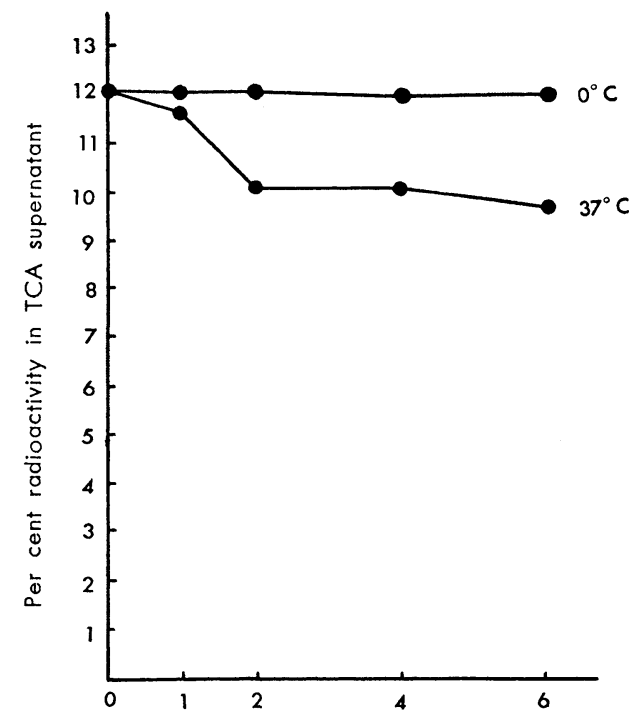

Time of preincubation of saliva in hrs. (at pH7.2)

Fig. 7. Effect of preincubation of saliva on its proteolytic activity

Preincubation was carried out by incubating the saliva at $37^{\circ} \mathrm{C}$ (control: $0^{\circ} \mathrm{C}$ ) and $\mathrm{pH}$ 7.2 for the designated periods. Proteolytic activity was measured by incubating the labeled casein (100 $\mu \mathrm{g} / \mathrm{ml}$ final concent.) and the preincubated saliva ( $1 / 2$ final concent.) at $37^{\circ} \mathrm{C}$ and $\mathrm{pH} 7.2$ for $1 \mathrm{hr}$. Final concent. of TCA-carrier casein was $6 \mathrm{mg} / \mathrm{ml}$.

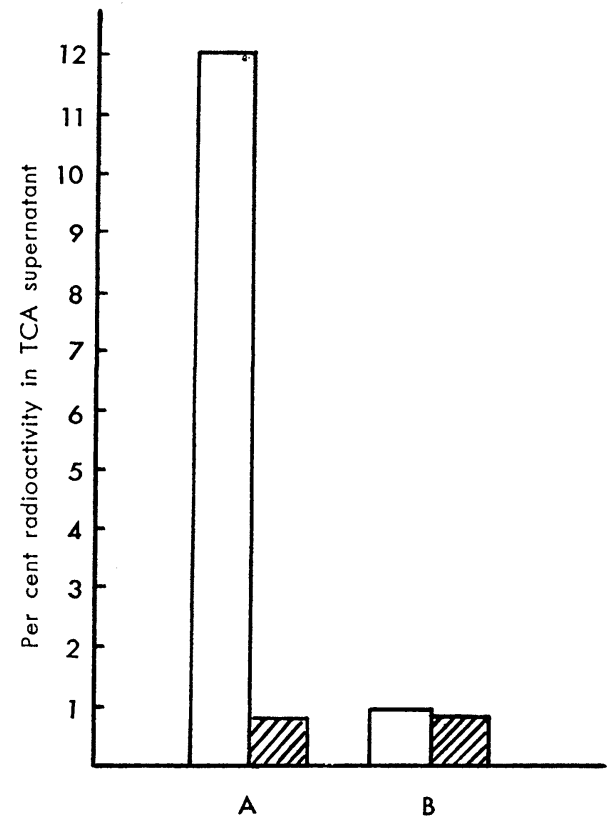

Fig. 8. Thermal inactivation of proteolytic activity of human saliva

A: Untreated saliva (control)

B: Saliva heated in boiling water for 30 mins.

Proteolytic activity was measured by incubating the saliva (untreated or heattreated, $1 / 2$ final concent.) at $37^{\circ} \mathrm{C}$ and $\mathrm{pH}$ 7.2 for $1 \mathrm{hr}$. (ख्या 


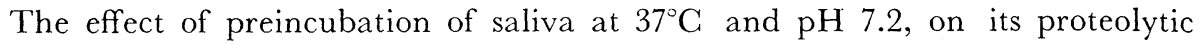
activity was expressed in Figure 7. Although a gradual decrease in the activity was observed, the protease in human saliva was found to be fairly stable at pH 7.2 .

The proteolytic activity completely disappeared after heating the saliva in boiling water for 30 mins. (Fig. 8).

In assaying the protease activity of human saliva, as measured by the per cent radioactivity in TCA supernatant, considerably large amounts of TCA-carrier casein (i.e. final concent. of $6 \mathrm{mg}$ per $\mathrm{ml}$ ) were used throughout all experiments. When smaller amounts of TCA-carrier casein (e.g. final concent. of $1 \mathrm{mg}$ per $\mathrm{ml}$ )

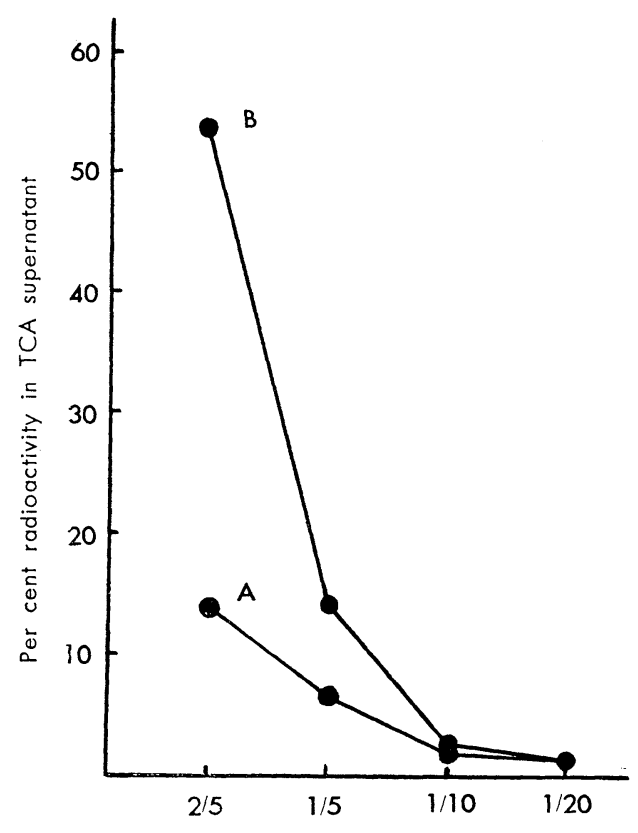

Final concent. of saliva (log. scale)

Fig. 9. Effect of concentration of untreated and boiled saliva on their "anti-TCA activity"

A: Untreated saliva

B: Boiled saliva (heated in boiling water for 30 mins.)

"Anti-TCA activity" was measured as follows: $\left.\right|^{131}$-casein $(100 \mu \mathrm{g} / \mathrm{ml}$ final concent.), saliva (the designated final concent.), and TCA-carrier casein $(1 \mathrm{mg} / \mathrm{ml}$ final concent.) were mixed at low temperature and $\mathrm{pH}$ 7.2. Equal volume of $10 \%$ TCA was added to the above solution and the per cent radioactivity in the supernatant was assayed.

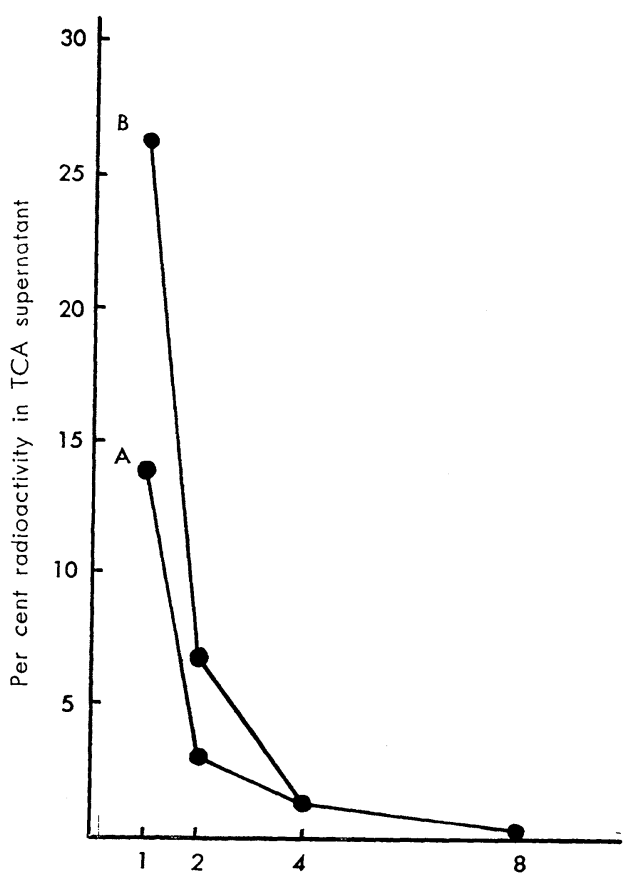

Final concent. of TCA-carrier casein ( $\mathrm{mg}$ per $\mathrm{ml}$ )

Fig. 10. Effect of concentration of TCAcarrier casein on the "anti-TCA activity" of untreated and boiled saliva

A: Untreated saliva

B: Boiled saliva (heated in boiling water for 30 mins.)

"Anti-TCA activity" was measured under the following conditions: $\left.\right|^{131}$-casein 100 $\mu \mathrm{g} / \mathrm{ml}$ final concent.), native or boiled saliva (1/2 final concent.), and TCA-carrier caseir (the designated final concent.). 
were used, remarkably large amount of radioactivity was observed in the TCA supernatant fluid of the nonincubated mixture of $\mathrm{I}^{131}$-casein $(100 \mu \mathrm{g} / \mathrm{ml}$ final concent.), TCA-carrier casein ( $\mathrm{lmg} / \mathrm{ml}$ final concent.), and saliva ( $1 / 2$ final concent.). This TCA supernatant radioactivity was increased even further when boiled saliva was used in place of untreated one. This unusual increase of the radioactivity in the TCA supernatant ("anti-TCA activity" of saliva) should not be considered as the result of the degradation of the labeled casein by saliva, but another cause must be seeked for. Figure 9 shows the effect of concentration of untreated and boiled saliva on their anti-TCA activity. Not only the boiled saliva exhibited higher anti-TCA activity than the untreated one, but remarkably rapid dropping of the activity was observed as the saliva was diluted.

The anti-TCA principle in untreated or boiled saliva was not precipitated at $\mathrm{pH} 4$ to 5 , but was almost insoluble in $80 \%$ acetone ( $\mathrm{pH} 5$ ). From these results, together with the finding that the antiTCA activity was not destroyed by boiling, salivary mucoid or its related substance was presumed to be responsible for the anti-TCA activity of saliva.

It was shown by Lineweaver and Murray (1947) that ovomucoid was resistant to precipitation by TCA. Jansen et al. (1952) found that cholinesterase prevented the precipitation of relatively small amounts of easily precipitable protein (e.g. $\beta$-lactoglobulin) by TCA, and that relatively large amounts of a carrier protein resulted in the complete precipitation of all the proteins including cholinesterase. The latter phenomenon was also reported by Michel and Krop (1951) using horse serum as carrier proteins.

Figure 10 illustrates the effect of various concentrations of TCA-carrier casein on the anti-TCA activity of

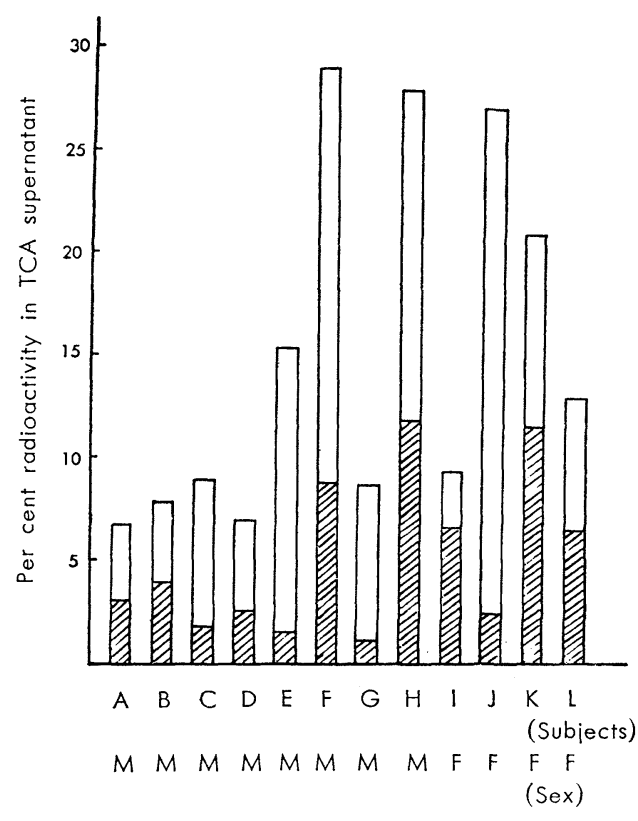

Fig. 11. Proteolyric and anti-TCA activities of saliva of twelve healthy persons

Proteolytic activity (i, i) was measured by incubating the $\mathrm{I}^{131}$-casein $(50 \mu \mathrm{g} / \mathrm{ml}$ final concent.) and saliva ( $1 / 2$ final concent.) ai $37^{\circ} \mathrm{C}$ and $\mathrm{pH} 7.2$ for 100 mins. Final concent. of TCA-carrier casein was $6 \mathrm{mg} / \mathrm{ml}$. "Anti-TCA activity" (BD) was measured under the following conditions: $\left.\right|^{131}$-casein $(50 \mu \mathrm{g} / \mathrm{ml}$ final concent.), saliva (1/2 final concent.), and TCA-carrier casein $(1 \mathrm{mg} / \mathrm{m}$ ! final concent.)

untreated and boiled saliva. Remarkably rapid dropping of the anti-TCA activity was observed as the concentration of the carrier casein increased. These results have made it possible to measure the real proteolytic activity of saliva, distinguished from the anti-TCA activity, using the sufficient amounts of TCA-carrier casein. Throughout all experiments, proteolytic activity was measured using TCA-carrier 
casein in the final concentration of $6 \mathrm{mg}$ per $\mathrm{ml}$, and it was always confirmed, in every experiment, that the radioactivity in the TCA supernatant fluid of the non-incubated mixture did not increase significantly.

Figure 11 shows the proteolytic and anti-TCA activities of saliva of twelve healthy persons, indicating large variations from person to person. As expressed in Figure 12, considerably large variations were also observed from day to day.

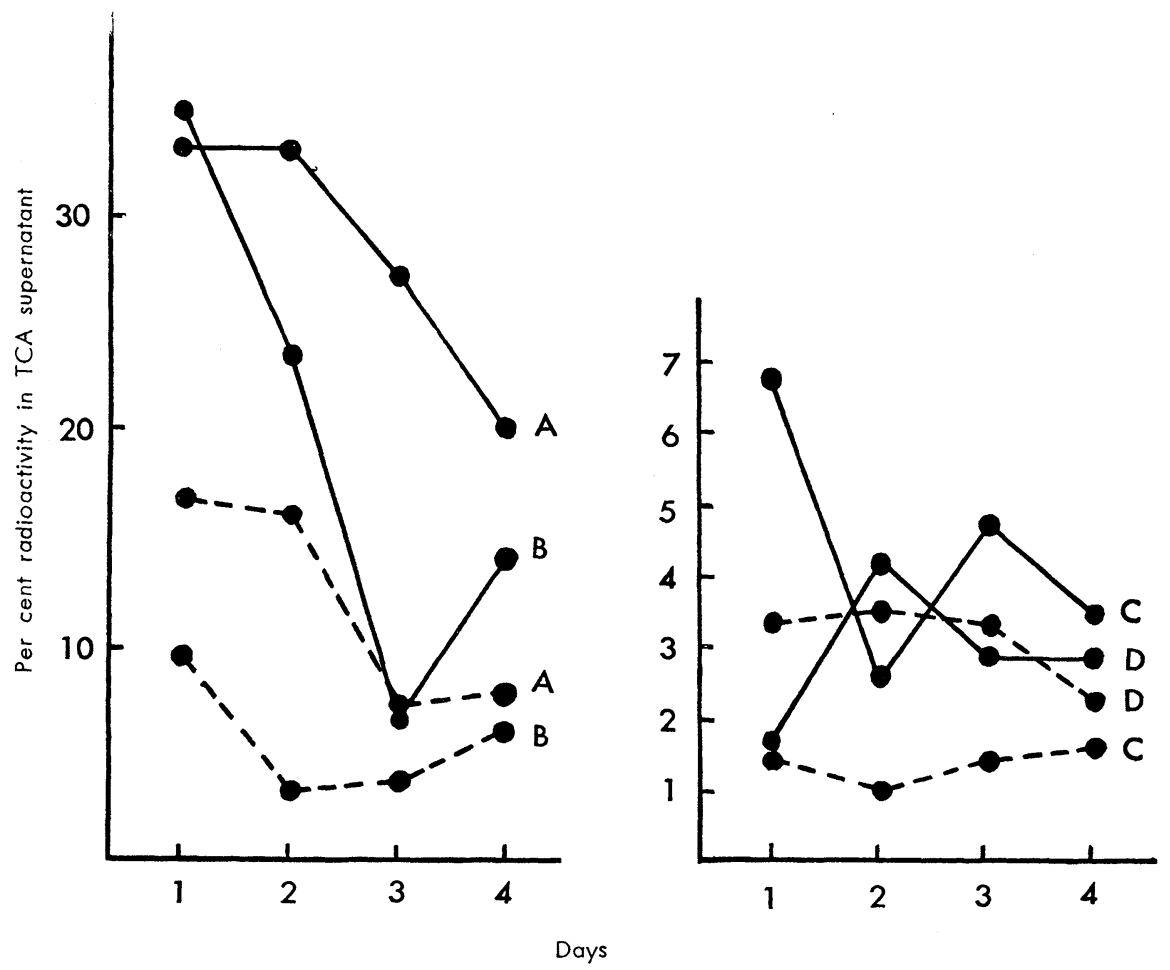

Fig. 12. Variations in proteolytic and anti-TCA activities of saliva of four individuals over a four day period

: Proteolyicic activity : Anti-TCA activity

Proteolytic and anti-TCA activities were measured by the methods described in the legend of Figure 11.

\section{SUMMARY}

Using I $^{131}$-labeled casein as substrate, the presence of proteolytic activity in human saliva was demonstrated, by measuring the increase of the radioactivity in the non-protein fraction of the incubation mixture and also by employing the 
so-called quantitative radio-paperchromatography.

This proteolytic activity of saliva had its optimal $\mathrm{pH}$ between 6 and 8 . It was fairly stable at $\mathrm{pH} 7.2$ and $37^{\circ} \mathrm{C}$, but was completely inactivated by heating the saliva in boiling water for 30 mins.

Besides the proteolytic activity, human saliva was found to possess the activity to prevent the precipitation of relatively small amounts of easily precipitable protein by TCA ("anti-TCA activity"), for which salivary mucoid or its related substanc was presumed to be responsible.

Considerably large variations in proteolytic and anti-TGA activities of saliva were observed from person to person as well as from day to day.

\section{ACKNOWLEDGMENT}

The authors are very grateful to Drs. H. Yoshikawa, Y. Yoneyama, and S. Minakami of the Department of Nutrition and Physiological Chemistry, the University of 'Tokyo, for their valuable advice and the kindness to permit the use of scintillation counter during the course of this study.

\section{REFERENCES}

Jansen, E.F., R. Jang, and A.K. Balls (1952). J. Biol. Chem. 196, 247.

Kim, Y.E. (1958). Endocrinol. Japon. 5: 208.

Lineweaver, H. and C.W. Murray (1947). J. Biol. Chem. 171, 565.

Michel, H.O. and S. Krop (1951). J. Biol. Chem. 190, 119.

Tanaka, S. and Y. Ito (1958). Endocrinol. Japon. 5, 55.

Voss, O. (1931). Zeitsch. f. physiol. Chem. 197, 42. 